\title{
Optimised synthesis of 6-iodoacetamidotetramethylrhodamine
}

\author{
V. Ranjit N. Munasinghe and John E. T. Corrie* \\ MRC National Institute for Medical Research, The Ridgeway, Mill Hill, London NW7 1AA, UK \\ E-mail: jcorrie@nimr.mrc.ac.uk
}

(received 8 Dec 05; accepted 11 Jan 06; published on the web 17 Jan 06)

\begin{abstract}
Practical improvements have been made to previous work on the synthesis of the title compound, particularly in the final step of converting its precursor chloroacetamide to the required iodoacetamide. Improvements include removal of contaminant(s) that inhibit the chloride to iodide exchange and better extraction procedures to minimise losses in work-up. The modified conditions for this step may be useful for synthesis of other thiol-reactive dyes where solubility of the dye is problematic.
\end{abstract}

Keywords: Rhodamine, iodoacetamide, halide exchange, fractional crystallisation

\section{Introduction}

Some time ago, one of us described the synthesis and characterisation of the pure 5- and 6isomers of iodoacetamidotetramethylrhodamine (compounds $\mathbf{1}$ and $\mathbf{2}$ respectively), ${ }^{1}$ that are useful for specific labelling of cysteine residues in proteins or peptides. These and other reactive rhodamine dyes are widely used in biological microscopy applications particularly because of their good fluorescence properties, specifically brightness and resistance to photobleaching.

Compounds 1 and 2 have been used for fluorescence polarisation studies on muscle fibres, ${ }^{2-4}$ for real-time imaging of single rhodamine fluorophores attached to actin in a functional assay, ${ }^{5}$ and more recently to provide fluorogenic assays for a malarial protease ${ }^{6}$ and for inorganic phosphate. ${ }^{7}$ The continuing interest in these compounds made it necessary to repeat the original synthesis in order to replenish stocks of material, but this brought to light several problems in reproducing aspects of the original experimental description. More positively, the reinvestigation has led to substantial improvements in protocol for the final synthetic step (conversion of a chloroacetamide to an iodoacetamide). These improvements were in the time to complete the exchange (reaction time of $4 \mathrm{~h}$ instead of 3 days), the product yield for this step ( 80\%) and in the batch-to-batch reliability, which we had previously found troublesome. This method may be of value in synthesis of other thiol-reactive dyes. For the benefit of future workers, we now report these modifications to the original published methods. 


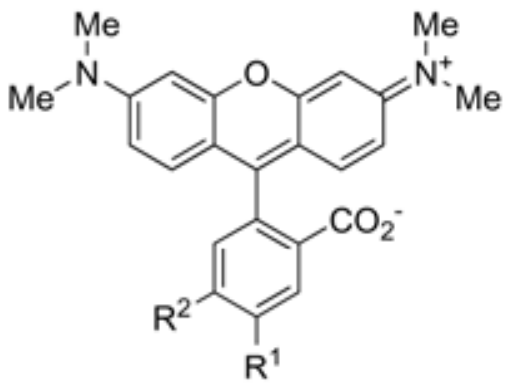

$1 \mathrm{R}^{1}=\mathrm{NHCOCH}_{2} \mathrm{l}, \mathrm{R}^{2}=\mathrm{H}$

$2 \mathrm{R}^{1}=\mathrm{H}, \mathrm{R}^{2}=\mathrm{NHCOCH}_{2} \mathrm{I}$

\section{Results and Discussion}

The initial stages of the synthesis are shown in Scheme 1, and in terms of reagents and general direction followed the methods previously described. ${ }^{1}$ However, aspects of experimental detail required modification to ensure successful execution of the synthesis. Thus isomerically-pure 4nitrophthalic anhydride 3 was prepared from commercial mixed isomers of nitrophthalic acid with minor modifications of published procedures as previously described, ${ }^{1}$ and condensed with 3-dimethylaminophenol 4. The crude product was esterified with methanol (catalysed by concentrated $\mathrm{H}_{2} \mathrm{SO}_{4}$ ) and the mixture of isomers 5 and 6 (ratio 4:6) was fractionally crystallised from methanol to give the pure 4-nitroisomer $\mathbf{5}$. In our earlier work, we had been able also to isolate the pure 5-nitro isomer $\mathbf{6}$ (the precursor of $\mathbf{1}$ ) but we were unable to reproduce this result. In practice, isolation of pure $\mathbf{5}$ was also troublesome. We eventually found this could be reliably achieved if the progress of fractional crystallisation from methanol was visually observed and the crystallisation mix was filtered at the point when red crystals of $\mathbf{6}$ began to contaminate the yellow crystals of $\mathbf{5}$ that deposited first. Two further crystallisations allowed isolation of pure $\mathbf{5}$. In contrast, repeated efforts to obtain the 5-nitro isomer 6 by crystallisation from ethanol, as previously described, ${ }^{1}$ were unsuccessful. The two isomers could be resolved by thin-layer chromatography (using multiple elutions) but this was not a practicable means to separate useful quantities of the 5-nitro isomer. In any event, both current applications ${ }^{6,7}$ of the iodoacetamidotetramethylrhodamine were better addressed with the 6-isomer 2 (i.e. that derived from 5), so there was no practical requirement to persevere with purification of $\mathbf{6}$.

The next stages of Scheme 1, i.e. reduction of the nitro group, acetylation of the resulting amine and hydrolysis of the methyl ester, resulting overall in the acid 7 , were readily reproduced without modification of the previous work. Furthermore, the TMS polyphosphate-mediated condensation of $\mathbf{7}$ with the dimethylaminophenol $\mathbf{4}$ was essentially unchanged, with the exception that the yield of isolated rhodamine was reliably maximised by removal of most of the DMF solvent and prolonged treatment of the remaining mixture with aqueous sodium hydroxide. Our previous account specified such treatment only for 5 minutes, but we have since found this 
inadequate to break down complexes of the product with the polyphosphate, and overnight treatment at ambient temperature was much more effective and reproducible. Also, the rhodamine 8 precipitated from the aqueous solution under these conditions and was recovered by filtration in a form suitable for purification by chromatography, thereby eliminating a troublesome extraction step.

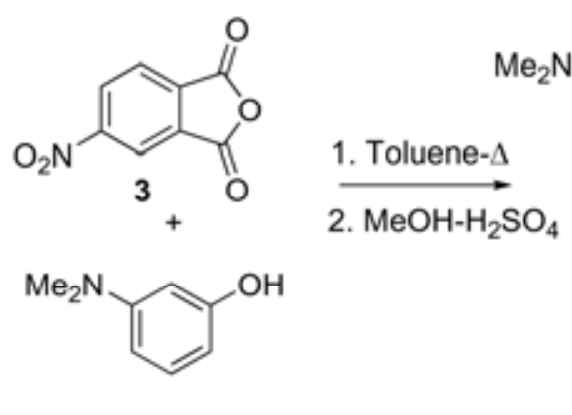

4

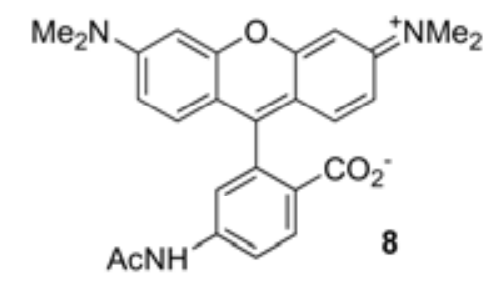

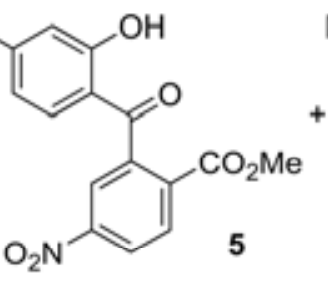<smiles>COC(=O)c1cc([N+](=O)[O-])ccc1C(=O)c1ccc(N(C)C)cc1O</smiles>

1. Fractional crystallisation

2. $\mathrm{H}_{2}-\mathrm{Pd} / \mathrm{C}$

3. $\mathrm{Ac}_{2} \mathrm{O}$-pyridine

4. $\mathrm{NaOH}$-aq. $\mathrm{MeOH}$

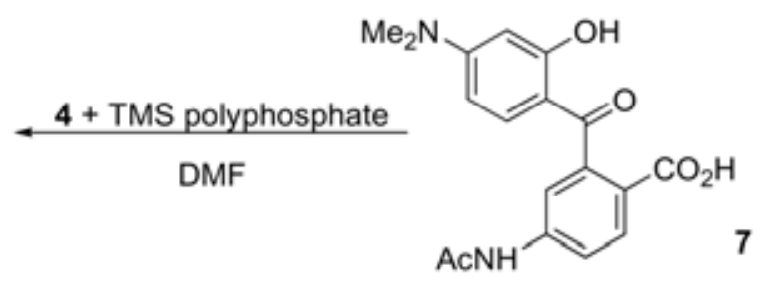

\section{Scheme 1}

The closing stages of the synthesis (Scheme 2) required hydrolysis of the acetamido group in 8 and re-acylation to give the chloroacetamide $\mathbf{9}$. The methodology was similar to that used previously, except that aqueous work-up of the hydrolysis procedure was eliminated and the crude amine product was used directly for chloroacetylation to give $\mathbf{9}$.

The last stage of the synthesis, an ostensibly trivial chloride/iodide interchange to give $\mathbf{2}$, was in practice the most recalcitrant. The problem came from the solubility properties of $\mathbf{9}$, which necessitated a solvent other than acetone, the normal solvent for such exchange reactions. The reaction at room temperature in methanol, as used previously, ${ }^{1}$ had always required a prolonged period for completion but material from the modified synthesis described here persistently failed to give complete exchange, even when the excess of sodium iodide was increased to a high level ( $100 \mathrm{mmol}$ per mmol of $\mathbf{9})$. We tried instead a recent procedure in refluxing methanol ${ }^{8}$ and later modified this to use a mixture of chloroform and methanol, in which the dye was fully soluble. Nevertheless, the extent of exchange was still variable and always incomplete. On re-examining the ${ }^{1} \mathrm{H}$ NMR spectrum of compound 9 as prepared here, we noted a singlet at $\delta 2.67$ that was not associated with any proton(s) in the structure of $\mathbf{9}$. We 
surmised that this impurity was possibly responsible for suppressing the exchange and found that it was removed by an aqueous wash of a solution of $\mathbf{9}$ in chloroform-methanol. Exchange of this material in chloroform-methanol under reflux then gave clean conversion to the iodoacetamide 2.

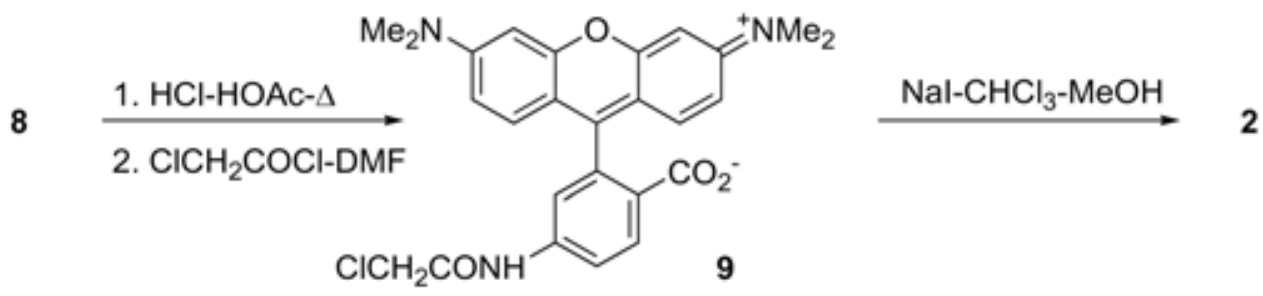

\section{Scheme 2}

While this satisfactorily achieved the conversion to iodo compound 2, the overall yield after the initial aqueous wash and subsequent extractive work-up procedures was poor. It was clear that considerable material was lost into the aqueous phase from the organic layer both during the pre-wash and in subsequent recovery from the exchange reaction. Although the usual expedient of using brine instead of water led to much-improved recovery, we were surprised to find that any exposure of either $\mathbf{9}$ or $\mathbf{2}$ to a brine wash either resulted in a failure of $\mathbf{9}$ to undergo full conversion to $\mathbf{2}$ or, apparently, partial reversion of $\mathbf{2}$ to $\mathbf{9}$. Carryover of chloride ion into the organic layer may be promoted by the methanol that was a necessary co-solvent with chloroform to keep the dye in solution during extraction. The problem was solved by substituting neutral 1.5 $\mathrm{M}$ potassium phosphate solution instead of brine, both for the aqueous wash and for work-up of the exchange reaction, whereupon the chloro to iodo conversion could readily be driven to completion and an overall recovery of $\sim 80 \%$ was obtained from the combined steps of the aqueous wash followed by the exchange reaction and extractive recovery of the product.

\section{Conclusions}

The procedures described here provide a reproducible and means to prepare the useful thiolreactive rhodamine derivative $\mathbf{2}$ with improved yields in several steps. Failure to reproduce in full the earlier fractional crystallisation of the isomeric benzoylbenzoates $\mathbf{5}$ and $\mathbf{6}$ means that the isomeric rhodamine $\mathbf{1}$ cannot readily be accessed by this route. This was unimportant for our immediate purpose but it is possible that access to these dyes (especially 1) might more readily be met by rational synthesis of $\mathbf{6}$ (and/or 5). More generally, the rapid chloride to iodide exchange in refluxing solvent, either in methanol alone as described ${ }^{8}$ or as modified here by incorporation of up to $30 \%$ chloroform, that was dictated by solubility of the rhodamine, is a useful alternative to conventional exchange in acetone solution when this is not applicable. 


\section{Experimental Section}

General Procedures. NMR spectra of rhodamines were determined on a Varian UnityPlus 500 spectrometer for solutions in $\mathrm{CDCl}_{3}-\mathrm{MeOH}-d_{4}$ (7:3). UV-vis measurements were made on a Beckman DU640 spectrophotometer in solutions of ethanol-water (9:1). Flash chromatography was on Merck 9385 silica gel. Trimethylsilyl polyphosphate was from Fluka, Gillingham, Dorset and all other reagents were from Aldrich. Organic extracts were dried over anhydrous $\mathrm{Na}_{2} \mathrm{SO}_{4}$. Quantities of $\mathbf{9}$ and $\mathbf{2}$ were determined spectrophotometrically, with solutions diluted in EtOH-water (9:1) and based on $\varepsilon_{549} 96,900 \mathrm{M}^{-1} \mathrm{~cm}^{-1}$ as previously determined. ${ }^{1}$

To keep all the information together, details of the full experimental protocol for Schemes 1 and 2 are given below, although parts of the procedures (mainly in the conversion of 5 to 7) do not differ significantly from steps previously described. ${ }^{1}$ Note also that, although rhodamine compounds are shown here as their open-chain, fluorescent tautomers, they are named as their spiro-lactone forms, as in the previous work. ${ }^{1}$

Methyl 2-(4'-dimethylamino-2'-hydroxybenzoyl)-4-nitrobenzoate (5). A solution of 4nitrophthalic anhydride 3 (33 g, 171 mmol, prepared as previously described ${ }^{1}$ ) and redistilled 3(dimethylamino)phenol 4 (24.2 g, $176.4 \mathrm{mmol})$ in dry toluene $(570 \mathrm{ml}$ ) was heated under reflux for $6 \mathrm{~h}$ and cooled. The solvent was evaporated and the residue was dissolved in $\mathrm{CHCl}_{3}$ and washed with $2 \mathrm{M} \mathrm{HCl}$. The organic phase was evaporated to give a purplish solid (54 g). A portion of the crude solid (12.0 g) was dissolved in hot $\mathrm{MeOH}$ (30 ml). The solution was cooled, diluted with $\mathrm{Et}_{2} \mathrm{O}(1250 \mathrm{ml})$ and left overnight at room temp. The solution was filtered from the purple precipitate and the filtrate was evaporated to give a mixture of the two acids corresponding to esters $\mathbf{5}$ and $\mathbf{6}$ as a yellow-orange solid. Processing the remaining material gave a total $49.7 \mathrm{~g}$ of this mixture and $1.0 \mathrm{~g}$ of purple residue that was discarded. A portion of the mixture of acids (23 g, $69.7 \mathrm{mmol}$ ) was dissolved in $\mathrm{MeOH}(470 \mathrm{ml})$ containing conc. $\mathrm{H}_{2} \mathrm{SO}_{4}$ $(13.2 \mathrm{ml})$ and the solution was refluxed for $8 \mathrm{~h}$. The methanol was evaporated and the residue was dissolved in $\mathrm{CHCl}_{3}$ (500 ml), washed successively with water (250 ml), saturated $\mathrm{NaHCO}_{3}$ $(3 \times 250 \mathrm{ml})$, water $(250 \mathrm{ml})$ and dried. The solvent was evaporated to give the 4-nitro and 5nitro esters 5 and 6 (21 g, 40:60 by ${ }^{1} \mathrm{H}$ NMR). The solid was refluxed with $\mathrm{MeOH}$ (1.2 l) for 2.5 $\mathrm{h}$ and the solution was allowed to cool for $2 \mathrm{~h}$, when the initial yellow crystalline deposit began to be overlaid by red crystalline material. The warm crystallisation mix was filtered to give a yellow solid (9.0 g, 63:37 ratio of 5 and 6). The red mother liquor contained 5 and $\mathbf{6}$ in a 29:71 ratio. The yellow solid was boiled with $\mathrm{MeOH}(600 \mathrm{ml})$, allowed to cool for $1 \mathrm{~h}$ and filtered to give 5 and 6 as a yellow solid (3.72 g, 90:10), which was dissolved in boiling $\mathrm{MeOH}$ (300 ml), allowed to cool overnight and filtered to give pure 5 (3.21 g, $9.33 \mathrm{mmol}, 5.5 \%)$. This material was identical to that previously described ${ }^{1}\left({ }^{1} \mathrm{H}\right.$ NMR, mp).

4-Acetamido-2-(4'-dimethylamino-2'-hydroxybenzoyl)benzoic acid (7). The ester 5 (3.1 g, $9.01 \mathrm{mmol})$ was dissolved in glacial acetic acid $(310 \mathrm{ml})$ and 10\% Pd-C (0.5 g) was added. The mixture was stirred under $\mathrm{H}_{2}$ at ambient temperature and pressure for $\sim 3 \mathrm{~h}$. The solution was 
warmed on a steam bath to redissolve precipitated material, filtered and evaporated. The residue ( $2.85 \mathrm{~g})$, was suspended in a mixture of pyridine $(50 \mathrm{ml})$ and acetic anhydride $(50 \mathrm{ml})$ and stirred overnight under nitrogen at room temp. The clear solution was evaporated in vacuo and the residue was dissolved in $\mathrm{CHCl}_{3}(150 \mathrm{ml})$, washed successively with $1 \mathrm{M} \mathrm{HCl}$, water, sat. $\mathrm{NaHCO}_{3}$ and water, dried and evaporated to an orange foam that was dissolved in $\mathrm{MeOH}$ (56 $\mathrm{ml}$ ). $10 \%$ aq. $\mathrm{NaOH}(12.5 \mathrm{~g}$ ) was added and the mixture was refluxed for $1.5 \mathrm{~h}$. The $\mathrm{MeOH}$ was evaporated, water ( $30 \mathrm{ml}$ ) was added and the solution acidified to $\mathrm{pH} 1.5$ with $5 \%$ aq. $\mathrm{H}_{2} \mathrm{SO}_{4}$. The precipitate was filtered, washed with $\mathrm{H}_{2} \mathrm{O}$ and dried in vacuo overnight to give the crude acetamido acid 7 (2.73 g, 84\%), which was crystallised from $\mathrm{MeOH}$ as brown platelets (2.15 g, $66 \%$ over 3 steps). This material was identical to that previously described ${ }^{1}\left({ }^{1} \mathrm{H}\right.$ NMR, mp).

\section{6-Acetamido-3',6'-bis(dimethylamino)spiro[1,3-dihydroisobenzfuran-1,9'-xanthen]-3-one}

(8). A solution of the acid 7 (0.8 g, $2.34 \mathrm{mmol})$, redistilled 3-(dimethylamino)phenol (0.96 g, 7.0 mmol) and trimethylsilyl polyphosphate $(2.2 \mathrm{~g})$ in dry DMF $(44 \mathrm{ml})$ was heated at $130{ }^{\circ} \mathrm{C}$ under nitrogen for $4 \mathrm{~h}$. The purple solution was cooled and the DMF was evaporated to about $1.5 \mathrm{ml}$ and stirred overnight at room temp. with $1 \mathrm{M} \mathrm{NaOH}(100 \mathrm{ml})$. The solution was filtered and the residue was dissolved in boiling $\mathrm{MeOH}(2 \times 200 \mathrm{ml}, 1 \times 100 \mathrm{ml})$. Silica gel $(2.5 \mathrm{~g})$ was added to the solution and the solvent was evaporated. The silica gel containing the absorbed compound was added to the top of a flash chromatography column $(100 \mathrm{~g})$ and successively eluted with mixtures of $\mathrm{MeOH}-\mathrm{CHCl}_{3}$ 10:90, 25:75, 40:60 to give 8 (593 mg,1.34 mmol, 57\%). ${ }^{1} \mathrm{H}$ NMR $\delta$ 8.08 (d, $1 \mathrm{H}, J=8.5 \mathrm{~Hz}, \mathrm{H}-4$ ), 7.80 (d, $1 \mathrm{H}, J=1.9 \mathrm{~Hz}, \mathrm{H}-7$ ), 7.55 (dd, $1 \mathrm{H}, J=8.5 \mathrm{~Hz}, 1.9 \mathrm{~Hz}, \mathrm{H}-$ 5), 7.19 (d, 2H, $\left.J=9.3 \mathrm{~Hz}, \mathrm{H}-1^{\prime}, 8^{\prime}\right), 6.79$ (dd, 2H, $\left.J=9.4 \mathrm{~Hz}, 2.4 \mathrm{~Hz}, \mathrm{H}-2^{\prime}, 7^{\prime}\right), 6.72$ (d, 2H, $J=$ $\left.2.4 \mathrm{~Hz}, \mathrm{H}-4^{\prime}, 5^{\prime}\right), 3.23$ (s, 12H, N-Me), 2.15 (s, 3H, $\mathrm{COCH}_{3}$ ).

6-Chloroacetamido-3',6'-bis(dimethylamino)spiro[1,3-dihydroisobenzofuran-1,9'-xanthen]3-one (9). The 6-acetamide 8 (1.0 mmol) was dissolved in a mixture of conc. $\mathrm{HCl}$-glacial $\mathrm{AcOH}$ $(140 \mathrm{ml}, 1: 1)$ and heated at reflux under nitrogen for $3 \mathrm{~h}$. The reaction mixture was evaporated to dryness in vacuo. Water $(25 \mathrm{ml})$ was added and the solution was again evaporated, then reevaporated from toluene $(3 \times 15 \mathrm{ml})$ and kept under vacuum for $1 \mathrm{~h}$. This dried purple powder was dissolved in dry DMF ( $40 \mathrm{ml})$, chloroacetyl chloride $(0.5 \mathrm{ml}, 6.28 \mathrm{mmol})$ was added and the solution was heated at $85{ }^{\circ} \mathrm{C}$ for $3.5 \mathrm{~h}$ under nitrogen. The cooled solution was evaporated to dryness, redissolved in a mixture of $\mathrm{CHCl}_{3}-\mathrm{MeOH}(40 \mathrm{ml}, 1: 1)$ and absorbed onto silica gel (2.5 g). The solvent was removed under reduced pressure and the silica gel containing the absorbed compound was added to the top of a flash chromatography column (200 g) that was successively eluted with $\mathrm{MeOH}-\mathrm{CHCl}_{3}$ mixtures 5:95, 10:90, 15:85, 20:80, 30:70. This column typically yielded 550-600 $\mu \mathrm{mol}$ of pure 6-chloroacetamido derivative 8. Rechromatography of mixed fractions gave a further $100-150 \mu \mathrm{mol}$ (total yield $310-360 \mathrm{mg}, 65-75 \%$ over 2 steps). As noted above, the material from this procedure contained an impurity characterised by a singlet in the ${ }^{1} \mathrm{H}$ NMR spectrum at $\delta$ 2.67. To provide material suitable for the next step, the recovered chloroacetamide 9 (377 $\mu \mathrm{mol})$ was dissolved in a mixture of $\mathrm{CHCl}_{3}-\mathrm{MeOH}(4: 1,240 \mathrm{ml})$ and washed with $1.5 \mathrm{M}$ aq. potassium phosphate, $\mathrm{pH} 7(2 \times 46 \mathrm{ml})$. MeOH $(2 \mathrm{ml})$ was added to the separating funnel to dissolve traces of flocculent solid that adhered to the walls and the twice- 
washed organic solution was added to this $\mathrm{MeOH}$ and washed once more with the phosphate buffer (46 ml). The organic solution was dried and evaporated to give the pure 6chloroacetamide $9(350 \mu \mathrm{mol})$ that was suitable for use in the final step. ${ }^{1} \mathrm{H}$ NMR $\delta 8.04(\mathrm{~d}, 1 \mathrm{H}$, $J=8.5 \mathrm{~Hz}, \mathrm{H}-4$ ), 7.80 (d, $1 \mathrm{H}, J=2.2 \mathrm{~Hz}, \mathrm{H}-7$ ), 7.49 (dd, $1 \mathrm{H}, J=8.6 \mathrm{~Hz}, 2.2 \mathrm{~Hz}, \mathrm{H}-5$ ), 7.19 (d, 2H, $\left.J=9.3 \mathrm{~Hz}, \mathrm{H}-1^{\prime}, 8^{\prime}\right), 6.77$ (dd, 2H, $\left.J=9.3 \mathrm{~Hz}, 2.4 \mathrm{~Hz}, \mathrm{H}-2^{\prime}, 7^{\prime}\right), 6.68$ (d, 2H, $J=2.4 \mathrm{~Hz}, \mathrm{H}-$ 4',5'), 4.12 (s, $2 \mathrm{H}, \mathrm{ClCH}_{2}$ ), 3.20 (s, $12 \mathrm{H}, \mathrm{N}-\mathrm{Me}$ ).

6-Iodoacetamido-3',6'-bis(dimethylamino)spiro[1,3-dihydroisobenzofuran-1,9'-xanthen]-3one (2). A solution of 9 (340 $\mu \mathrm{mol})$ in a mixture of $\mathrm{MeOH}-\mathrm{CHCl}_{3}(7: 3,20.4 \mathrm{ml})$ that contained $\mathrm{NaI}$ (2.55 g, $17 \mathrm{mmol}$ ) was refluxed for $4 \mathrm{~h}$ under nitrogen. The cooled solution was diluted with $\mathrm{CHCl}_{3}-\mathrm{MeOH}(4: 1,250 \mathrm{ml})$ and washed successively with $5 \%$ sodium ascorbate in $1.5 \mathrm{M}$ potassium phosphate, $\mathrm{pH} 7(40 \mathrm{ml})$ and $1.5 \mathrm{M}$ potassium phosphate, $\mathrm{pH} 7(2 \times 40 \mathrm{ml})$. $\mathrm{MeOH}(2$ $\mathrm{ml}$ ) was added to the separating funnel as for $\mathbf{8}$ above, and the twice-washed organic solution was added to this $\mathrm{MeOH}$ and washed once more with the phosphate buffer $(46 \mathrm{ml})$. The solution was dried and evaporated under reduced pressure to give the iodoacetamide 2 as a purple solid (175 mg, $306 \mu \mathrm{mol}, 90 \%) .{ }^{1} \mathrm{H}$ NMR $\delta 8.04$ (d, $\left.1 \mathrm{H}, J=8.5 \mathrm{~Hz}, \mathrm{H}-4\right), 7.81$ (d, $1 \mathrm{H}, J=2.0 \mathrm{~Hz}, \mathrm{H}-$ 7), 7.45 (dd, $1 \mathrm{H}, J=8.6 \mathrm{~Hz}, 2.2 \mathrm{~Hz}, \mathrm{H}-5$ ), 7.18 (d, 2H, $J=9.3 \mathrm{~Hz}, \mathrm{H}-1$ ',8'), 6.77 (dd, 2H, $J=9.3$ Hz, 2.4 Hz, H-2',7'), 6.69 (d, 2H, $J=2.4$ Hz, H-4',5'), 3.84 (s, 2H, $\mathrm{ICH}_{2}$ ), 3.20 (s, 12H, N-Me).

\section{Acknowledgements}

We are grateful to the MRC Biomedical NMR Centre for access to facilities.

\section{References}

1. Corrie, J.E.T.; Craik, J.S. J. Chem. Soc., Perkin Trans. 1 1994, 2967.

2. Irving, M.; Allen, T.S.; Sabido-David, C.; Craik, J.S.; Brandmeier, B.; Kendrick-Jones, J.; Corrie, J.E.T.; Trentham. D.R.; Irving, M. Nature 1995, 375, 688.

3. Berger, C.L., Craik, J.S.; Trentham. D.R.; Corrie, J.E.T.; Goldman, Y.E. Biophys. J. 1996, 71, 3330.

4. Martyn, D.A.; Regnier, M.; Xu, D.G.; Gordon, A.M. Biophys. J. 2001, 80, 360.

5. Sase, I.; Miyata, A.; Corrie, J.E.T.; Craik, J.S.; Kinosita, K. Biophys. J. 1995, 69, 323.

6. Blackman, M.J.; Corrie, J.E.T.; Croney, J.C.; Kelly, G.; Eccleston, J.F.; Jameson, D.M. Biochemistry, 2002, 41, 12244.

7. Okoh, M.P.; Hunter, J.L.; Corrie, J.E.T.; Webb, M.R. unpublished data.

8. Toutchkine, A.; Kraynov, V.; Hahn, K. J. Am. Chem. Soc. 2003, 125, 4132. 